OPEN ACCESS

Edited by: George Grant, University of Aberdeen, United Kingdom

Reviewed by:

Claudia Maria Hemsley, University of Exeter, United Kingdom Mário Hüttener, University of Barcelona, Spain

*Correspondence: Liliana Cruz Spano liliana.spano@ufes.br

Specialty section: This article was submitted to

Infectious Diseases,

a section of the journal

Frontiers in Microbiology

Received: 17 April 2019

Accepted: 19 July 2019

Published: 13 August 2019

Citation:

Guerrieri CG, Pereira MF, Galdino ACM, Santos ALS, Elias WP.

Schuenck RP and Spano LC (2019) Typical and Atypical Enteroaggregative Escherichia coli Are Both Virulent in the Galleria mellonella Model. Front. Microbiol. 10:1791. doi: 10.3389/fmicb.2019.01791

\section{Typical and Atypical} Enteroaggregative Escherichia coli Are Both Virulent in the Galleria mellonella Model

\author{
Caroline Gastaldi Guerrieri', Monalessa Fábia Pereira ${ }^{1}$, Anna Clara Milesi Galdino², \\ André Luis Souza dos Santos ${ }^{2}$, Waldir Pereira Elias ${ }^{3}$, Ricardo Pinto Schuenck ${ }^{1}$ and \\ Liliana Cruz Spano ${ }^{*}$
}

\begin{abstract}
1 Laboratory of Virology and Infectious Gastroenteritis, Department of Pathology, Health Sciences Center, Federal University of Espírito Santo, Vitória, Brazil, ${ }^{2}$ Laboratory of Advanced Studies of Emerging and Resistant Microorganisms, Department of General Microbiology, Institute of Microbiology Paulo de Góes, Federal University of Rio de Janeiro, Rio de Janeiro, Brazil, ${ }^{3}$ Laboratory of Bacteriology, Butantan Institute, São Paulo, Brazil
\end{abstract}

Enteroaggregative Escherichia coli (EAEC) is an emerging pathotype responsible for acute and persistent diarrhea. It can be classified as typical and atypical strains, respectively, based on the presence or absence of the AggR regulon, suggesting a higher virulence for typical EAEC. This study aims to evaluate in the Galleria mellonella model if there are differences in the virulence profiles among clinical strains of typical and atypical EAEC, prototype strains EAEC C1096, 042 and its aggR mutant. The clinical EAEC strains $(n=20)$ were analyzed for the presence of 22 putative virulence factors of EAEC or extraintestinal $E$. coli by PCR, as well as phenotypic characteristics of virulence (enzymes, siderophore, and biofilm). The survival of the larvae was analyzed after inoculation of $10^{4}-10^{7} \mathrm{CFU} /$ larva; the monitoring of bacterial growth in vivo and hemocyte quantification was determined after inoculation of the prototype strains (10 ${ }^{5} \mathrm{CFU} / \mathrm{larva}$ ) at different periods after infection. The strains of typical and atypical EAEC presented the same virulence profile for the larva, regardless of the amount or type of genes and phenotypic aspects of virulence analyzed. In addition, the EAEC 042 aggR mutant strain showed a significant reduction in the mortality of the inoculated larvae compared to the wild-type strain. In conclusion, the results obtained herein demonstrate that the virulence of EAEC seems to be related to the AggR regulon, but not exclusively, and atypical EAEC strains may be as virulent as typical ones in vivo in the G. mellonella model.

Keywords: enteroaggregative E. coli, bacterial pathogenesis, Galleria mellonella, infection model, AggR regulon

\section{INTRODUCTION}

Enteroaggregative Escherichia coli (EAEC), one of the six diarrheagenic pathotypes of E. coli, has been the most frequent cause of acute and persistent diarrhea in people of all ages in several regions of the world, including Brazil, corresponding to between 21 and 25\% of cases (Moreno et al., 2010; Okhuysen and Dupont, 2010; Lozer et al., 2013; Spano et al., 2017). EAEC, a heterogeneous 
pathogen that remains misunderstood, has a proposed pathogenesis comprising initial adhesion, biofilm formation, induction of an inflammatory response, and release of toxins; however, putative virulence factors are not uniformly present in all isolated strains (Okeke et al., 2000, 2010; Navarro-Garcia et al., 2010; Jensen et al., 2014).

Presence of AggR regulon distinguishes typical from atypical EAEC, since it regulates both chromosomal and plasmidencoded virulence factors. In this sense, typical EAEC is suggested to be more virulent and more likely to cause diarrhea in humans than atypical EAEC (Sarantuya et al., 2004; Morin et al., 2013). However, atypical EAEC has also been reported as an enteric pathogen of significant outbreaks (Čobeljić et al., 1996; Itoh et al., 1997). In general, the typical EAEC strains are more frequent than the atypical EAEC, but, interestingly, some studies have demonstrated a higher frequency for atypical, varying from between 57.3 and $73.7 \%$, compared to the typical ones, that range from between 26.3 and 42.7\% (Huang et al., 2003, 2007; Opintan et al., 2010; Spano et al., 2017). There is still a gap in understanding their virulence aspects and we believe that wellestablished in vivo models may contribute to elucidate a possible difference between these two groups.

For ethical reasons, studies with human volunteers that would best reproduce bacterial virulence is not currently feasible (Nataro et al., 1995), therefore, studies make use of animal models, mainly rodents, as a way to investigate aspects of the EAEC pathogenesis and, in recent years, for ethical and costs reasons, the use of invertebrate models has been implemented for studies of several microorganisms, even for EAEC (Morin et al., 2010; Roche et al., 2010; França et al., 2013; Jønsson et al., 2016; Khalil et al., 2016). In this context, the larvae of Galleria mellonella (Lepidoptera: Pyralidae) shows several morphological, physiological and immunological advantages over other invertebrate models (Tsai et al., 2016). Their relatively larger size (between 12 and $20 \mathrm{~mm}$ ), in comparison to other invertebrate models, makes the larvae easier to handle for injecting the inoculum directly into the larval haemocoel, and removing tissues and hemolymph for subsequent analysis (Cook and Mcarthur, 2013). Besides, the survival of G. mellonella at $37^{\circ} \mathrm{C}$ allows investigating temperature-dependent virulence factors, and its immune system shares a high degree of structural and functional similarities to the innate immune system of vertebrates, being hemocytes analogous to human phagocytes (Ramarao et al., 2012; Tsai et al., 2016). In addition to the hemocyte-mediated cellular immune response, G. mellonella also has a humoral immune response consisting of effector molecules, including opsonins (Park et al., 2005; Shaik and Sehnal, 2009), antimicrobial peptides (Lee et al., 2004; Brown et al., 2009), and melanin (Soderhall and Cerenius, 1998). Previously, Jønsson et al. (2016) and Khalil et al. (2016) analyzed only typical EAEC strains in this same model, comparing it with non-pathogenic E. coli and validating the model for EAEC pathogenicity studies.

Therefore, we analyzed, in the G. mellonella model, if there are differences in virulence profiles among prototype and clinical strains of both typical and atypical EAEC, duly characterized for phenotypic and genotypic aspects, and mutant strain for the $\operatorname{aggR}$ gene.

\section{MATERIALS AND METHODS}

\section{Bacterial Strains}

Twenty EAEC strains were analyzed, ten typical and ten atypical, obtained from stool samples of children up to 11 years of age, with $(n=4)$ and without diarrhea $(n=16)$, during a previous epidemiological study conducted from August 2007 to September 2008 in a rural area of Southeastern Brazil (Lozer et al., 2013). EAEC was identified by its aggregative adherence pattern in a HEp-2 cell culture; typical and atypical EAEC strains were classified according to the presence or absence of $\operatorname{aggR}$, respectively (Lozer et al., 2013). Bacterial cultures were kept at $-20^{\circ} \mathrm{C}$ in $24 \%(\mathrm{w} / \mathrm{v})$ sucrose solution.

The prototype strains EAEC 042 (typical), C1096 (atypical), non-pathogenic E. coli strain HB101 and an aggR isogenic mutant of EAEC 042 (Nataro et al., 1995; Cobeljić et al., 1996; Elias et al., 1999) were all included in the study. EAEC 042 and HB101 were kindly provided by Dr. Isabel Scaletsky (Federal University of São Paulo, Brazil).

\section{Genotypic and Phenotypic Characterization of EAEC Strains Detection of Virulence Genes by Polymerase Chain Reaction (PCR)}

The 20 EAEC strains were screened by PCR for the presence of 17 putative virulence factors described for EAEC as those related to bacterial adhesion, toxin production, iron uptake, and biofilm production, for which the target genes, sequences of primers, amplicon sizes, and control strains are shown in Table 1. Besides that, all EAEC strains, including the prototypes EAEC 042 and C1096, were analyzed for extraintestinal virulence markers to detect some virulence genes used to classify E. coli strains as extraintestinal pathogenic E. coli (ExPEC), according to Johnson et al. (2003), i.e., papC, sfa, afaC, iutA, and kpsMTII.

Bacterial DNA was extracted by boiling a suspension of 1 colony in $50 \mu \mathrm{l}$ of distilled water. All the reactions were carried out in a final volume of $25 \mu \mathrm{l}$ with $5 \mu \mathrm{l}$ of extracted DNA $(10 \mathrm{ng} / \mu \mathrm{l})$, reaction buffer, $1.5 \mathrm{~mm}$ of $\mathrm{MgCl}_{2}, 200 \mu \mathrm{m}$ of each $\mathrm{dNTP}, 0.02 \mathrm{U} / \mu \mathrm{l}$ of DNA Taq polymerase ${ }^{\mathrm{TM}}$ (Invitrogen) and $0.4 \mu \mathrm{m}$ of each primer, except for $0.16 \mu \mathrm{m}$ of $\operatorname{set} 1 A$, ast $A$, and pet primers used in a multiplex reaction (Table 1), $0.3 \mu \mathrm{m}$ of $k p s M T I I$ and 0.6 for iutA.

Amplifications were performed in a Veriti ${ }^{\circledR}$ Thermal Cycler (Applied Biosystems ${ }^{\circledR}$ ) and the amplicons observed after electrophoresis in 1.5\% agarose gels in Tris-borate-EDTA (TBE) buffer $0.5 \mathrm{X}$, stained with ethidium bromide.

\section{Siderophore and Hydrolytic Enzymes Production Assays}

The production of siderophore and hydrolytic enzymes (phospholipase, esterase, protease, and hemolysin) were investigated, starting from $200 \mu \mathrm{l}$ of bacterial suspension at the concentration of $1.5 \times 10^{8} \mathrm{CFU} / \mathrm{ml}$, added to $2 \mathrm{ml}$ of Luria Bertani (LB) (Kasvi) broth and incubated at $37^{\circ} \mathrm{C}$ for $24 \mathrm{~h}$. Then, $5 \mu \mathrm{l}$ of the suspension were applied to the center of Petri dishes with chrome azurol S agar (CAS) for siderophore assay or culture 
TABLE 1 | Primers, amplicon sizes, and control strains to virulence genes detection.

\begin{tabular}{|c|c|c|c|c|c|}
\hline Gene & Encoded protein & Primer pair $\left(5^{\prime}-3^{\prime}\right)$ & Control strain & Amplicon size (pb) & References \\
\hline $\operatorname{aggA}$ & AAF/I fimbrial subunit & $\begin{array}{l}\text { TTAGTCTTCTATCTAGGG } \\
\text { AAATTAATTCCGGCATGG }\end{array}$ & EAEC 17-2 & 450 & Czeczulin et al., 1999 \\
\hline aafA & AAF/II fimbrial subunit & $\begin{array}{l}\text { ATGTATIITAGAGGTTGAC } \\
\text { TATTATATTGTCACAAGCTC }\end{array}$ & EAEC 042 & 518 & \\
\hline $\operatorname{agg} 3 A$ & AAF/III fimbrial subunit & $\begin{array}{l}\text { GTATCATTGCGAGTCTGGTATTCAG } \\
\text { GGGCTGTTATAGAGTAACTTCCAG }\end{array}$ & E. coli RN785-1 & 462 & Bernier et al., 2002 \\
\hline $\operatorname{agg} 4 \mathrm{~A}$ & AAF/IV fimbrial subunit & $\begin{array}{l}\text { TCCATTATGTCAGGCTGCAA } \\
\text { GGCGTTAACGTCTGATTCC }\end{array}$ & Personal collection & 411 & Boisen et al., 2008 \\
\hline $\operatorname{aggR}$ & EAEC transcriptional activator & $\begin{array}{l}\text { CTAATTGTACAATCGATGTA } \\
\text { ATGAAGTAATTCTTGAAT }\end{array}$ & EAEC 042 & 308 & Czeczulin et al., 1999 \\
\hline aаp & Antiaggregation protein (dispersin) & $\begin{array}{l}\text { CगITCTGGCATCTTGGGT } \\
\text { GTAACAACCCCTIGGAAGT }\end{array}$ & EAEC 042 & 232 & \\
\hline shf & Cryptic ORF & $\begin{array}{l}\text { АCTाCTCCCGAGACATTC } \\
\text { CПTAGCGGGAGCATTCAT }\end{array}$ & EAEC 042 & 613 & \\
\hline hlyA & $\alpha$-haemolysin & $\begin{array}{l}\text { CTCATTGGCCTCACCGAACGG } \\
\text { GCTGGCAGCTGTGTCCACGAG }\end{array}$ & Personal collection & 299 & Guignot et al., 2000 \\
\hline irp2 & Yersiniabactin biosynthetic gene & $\begin{array}{l}\text { AAGGATTCGCTGTTACCGGAC } \\
\text { TCGTCGGGCAGCGTITCTCT }\end{array}$ & E. coli RN785-1 & 264 & Czeczulin et al., 1999 \\
\hline sen & Shigella enterotoxin2 & $\begin{array}{l}\text { ATGTGCCTGCTATTATITAT } \\
\text { CATAATAATAAGCGGTCAGC }\end{array}$ & Personal collection & 799 & Vila et al., 2000 \\
\hline $\operatorname{agn} 43$ & Antigen 43 & $\begin{array}{l}\text { ACGCACAACCATCAATAAAA } \\
\text { CCGCCTCCGATACTGAATGC }\end{array}$ & EAEC 042 & 600 & Mendez-Arancibia et al., 2008 \\
\hline sat & Secreted auto transporter toxin & $\begin{array}{l}\text { ACTGGCGGACTCATGCTGT } \\
\text { AACCCTGTAAGAAGACTGAGC }\end{array}$ & Shigella flexneri MA245-5 & 387 & Ruiz et al., 2002 \\
\hline ast $A$ & EAEC heat-stable enterotoxin 1 & $\begin{array}{l}\text { CCATCAACACAGTATATCCGA } \\
\text { GGTCGCGAGTGACGGCTITGT }\end{array}$ & EAEC 042 & 111 & Huang et al., 2007* \\
\hline pet & Plasmid encoded toxin & $\begin{array}{l}\text { GACCATGACCTATACCGACAGC } \\
\text { CCGATITCTCAAACTCAAGACC }\end{array}$ & EAEC 042 & 600 & \\
\hline $\operatorname{set1} A$ & Shigella enterotoxin1 & $\begin{array}{l}\text { TCACGCTACCATCAAAGA } \\
\text { TATCCCCCTITGGTGGTA }\end{array}$ & EAEC 042 & 309 & \\
\hline chuA & E. coli haem utilization gene & $\begin{array}{l}\text { ATCTGCTGCGTCATGTTCCT } \\
\text { GTAGTGGTCATACCTTGAGC }\end{array}$ & E. coli EDL933 & 1700 & Okeke et al., 2004* \\
\hline iucA & Aerobactin siderophore & $\begin{array}{l}\text { AGTCTGCATCTTAACCTTCA } \\
\text { CTCGTTATGTCGTTCAGAT }\end{array}$ & Shigella flexneri MA245-5 & 1100 & \\
\hline $\mathrm{afaC}$ & Afa/Dr adhesin & $\begin{array}{l}\text { CGGCTITCTGCTGAACTGGCAGGC } \\
\text { CCGTCAGCCCCCACGGCAGACC }\end{array}$ & C1845 & 672 & Le Bouguenec et al., 2001 \\
\hline papC & P fimbriae & $\begin{array}{l}\text { GACGGCTGTACTGCAGGGTGTGGCG } \\
\text { ATATCCTICTGCAGGGATGCAATA }\end{array}$ & E. coli J96 & 328 & Le Bouguenec et al., 1992* \\
\hline sfa & S fimbriae & $\begin{array}{l}\text { CTCCGGAGAACTGGGTGCATCTTAC } \\
\text { CGGAGGAGTAATTACAAACCTGGCA }\end{array}$ & E. coli J96 & 410 & \\
\hline iutA & Aerobactin receptor & $\begin{array}{l}\text { GGCTGGACATCATGGGAACTGG } \\
\text { CGTCGGGAACGGGTAGAATCG }\end{array}$ & Shigella flexneri SA101 & 300 & Johnson and Stell, 2000* \\
\hline kpsMTII & Group 2 capsule synthesis & $\begin{array}{l}\text { GCGCATTTGCTGATACTGTTG } \\
\text { CATCCAGACGATAAGCATGAGCA }\end{array}$ & E. coli HB101 & 272 & \\
\hline
\end{tabular}

*Multiplex PCR.

media containing the substrate for the hydrolytic enzyme to be tested, followed by incubation at $37^{\circ} \mathrm{C}$ for $48 \mathrm{~h}$. The culture media compositions were: (i) Phospholipase - glucose $20 \mathrm{~g} / \mathrm{L}$, yeast extract $5 \mathrm{~g} / \mathrm{L}$, peptone $10 \mathrm{~g} / \mathrm{L}, \mathrm{NaCl} 40 \mathrm{~g} / \mathrm{L} \mathrm{CaCl}_{2} 0.74 \mathrm{~g} / \mathrm{L}$, bacteriological agar $15 \mathrm{~g} / \mathrm{L}$, and $2 \%$ (w/v) egg yolk; (ii) Protease tryptone $10 \mathrm{~g} / \mathrm{L}, \mathrm{NaCl} 10 \mathrm{~g} / \mathrm{L}$, yeast extract $5 \mathrm{~g} / \mathrm{L}$, bacterial agar $12 \mathrm{~g} / \mathrm{L}+1 \%(\mathrm{w} / \mathrm{v})$ skimmed milk powder; (iii) Esterase peptone $10 \mathrm{~g} / \mathrm{L}, \mathrm{NaCl} 5 \mathrm{~g} / \mathrm{L}, \mathrm{CaCl}_{2} .2 \mathrm{H}_{2} \mathrm{O} 0.1 \mathrm{~g} / \mathrm{L}$, bacteriological agar 15 g/L Tween 8010 ml/L; (iv) Hemolysin - blood agar 5\% sheep red blood cell - Merckoplate ${ }^{\circledR}$. Siderophore production was observed by the formation of an orange halo around the colony, and enzymatic activity by the formation of a halo of degradation. All assays were quantified by the ratio between colony and halo diameter $\left(D_{\text {colony }} / D_{\text {halo }}\right)$ and classified as a weak, good or excellent producer, as previously described (Price et al., 1982; Searle et al., 2015; Ramos et al., 2016).

\section{Biofilm Formation Assay}

The biofilm formation assay was performed as described by Sheikh et al. (2001), with some modifications. In summary, a colony of each strain obtained on nutrient agar (Kasvi) was suspended in $2 \mathrm{ml}$ of $\mathrm{LB}$ broth and incubated at $37^{\circ} \mathrm{C}$ for 
$18 \mathrm{~h}$ at $110 \mathrm{rpm}$. The suspension was then adjusted to a concentration of $1.5 \times 10^{8} \mathrm{CFU} / \mathrm{ml}$, and $2 \mu \mathrm{l}$ of it was added to $200 \mu \mathrm{l}$ of Dulbecco's Modified Eagle's Medium (DMEM) (Cultilab) supplemented with $0.4 \%(\mathrm{w} / \mathrm{v})$ of glucose in a 96-well polystyrene microplate. The microplates were incubated at $37^{\circ} \mathrm{C}$ for $24 \mathrm{~h}$ for biofilm formation, which was fixed with methanol and stained with crystal violet. Bound crystal violet was solubilized by adding $100 \mu \mathrm{l}$ of $97 \%$ ethanol in ether (v/v) and the biofilm was quantified by absorbance measure at $540 \mathrm{~nm}$ (EZ Read 400 microplate reader). Biofilm classification as "forming" and "nonforming” was performed according to Stepanovic et al. (2007).

\section{In vivo Assays in G. mellonella Model G. mellonella Killing Assay}

All EAEC clinical and prototype strains at mid-exponential phase were injected into $G$. mellonella larvae in concentrations ranging from $10^{4}$ to $10^{7} \mathrm{CFU} /$ larva. The experiments were carried out according to Ramarao et al. (2012). Each concentration was tested on 20 last-instar larvae, each weighing 250-300 mg, and each larva was inoculated with $10 \mu \mathrm{l}$ of bacterial suspension into the haemocoel using insulin syringes (Becton Dickinson). Infected larvae were placed in Petri dishes, incubated at $37^{\circ} \mathrm{C}$, and mortality was monitored every $24 \mathrm{~h}$ for up to $96 \mathrm{~h}$ after infection. Larvae that did not respond to touch were considered dead. The negative control consisted of larvae inoculated with sterile PBS and non-pathogenic E. coli strain HB101. The experiment was performed in triplicate on different days. The strains were classified as highly virulent when less than $40 \%$ of the larvae survived at the end of the experiment with $10^{5} \mathrm{CFU} /$ larva, and as moderate or low virulence when between 40 and $60 \%$ and more than $60 \%$ of the larvae survived, respectively.

\section{Monitoring of Bacterial Growth in vivo}

Bacterial growth monitoring was performed for the prototype strains (EAEC C1096, 042 and its $\operatorname{aggR}$ mutant) and the non-pathogenic E. coli strain HB101, as described by Pereira et al. (2015). The strains were inoculated into haemocoel of G. mellonella larvae at the concentration of $10^{5} \mathrm{CFU} /$ larva. The concentration of bacteria into the hemolymph was monitored at $0,2,4,6$, and $24 \mathrm{~h}$ after infection. At each time, $10 \mu \mathrm{l}$ of hemolymph were removed by a cut near the pseudo legs after larval surface antisepsis with 70\% ethanol, and 10-fold dilutions of each strain were plated on MacConkey agar (Oxoid) and incubated at $37^{\circ} \mathrm{C}$ for $24 \mathrm{~h}$. The negative control consisted of larvae inoculated with sterile PBS. This procedure was performed for three larvae individually, for each strain at each time, and in a total of three replicates on different days. To calculate the bacterial concentration in CFU, the mean of the tested larvae was considered.

\section{Hemocyte Quantification During Infection}

Hemocyte quantification was performed according to Pereira et al. (2015). Briefly, $10 \mu \mathrm{l}$ of hemolymph, obtained from the inoculated larvae as described above, were transferred to microcentrifuge tubes previously treated with Sigmacote (Sigma-Aldrich) containing anticoagulant solution with $\mathrm{pH}$ 4.5 (Mead et al., 1986). Hemocyte count was performed in a
Neubauer chamber under an optical microscope. The negative controls consisted of uninfected, infected with E. coli HB101 and inoculated with sterile PBS larvae. This procedure was performed in four larvae individually for each strain at each time, and the hemocytes concentration was calculated as the mean of the tested larvae.

\section{Data and Statistical Analyses}

To analyze virulence in G. mellonella model, survival curves were made using the Kaplan-Meier method. The Log-Rank test was performed to observe if there was a significant difference in survival curves and Student's $t$-test was performed to analyze the survival percentage after $96 \mathrm{~h}$, the difference in the production of hydrolytic enzymes, siderophores, and biofilm between the typical and atypical strains. The Spearman's correlation and the chi-square tests were used to investigate if there was a correlation between the amount or kind of virulence genes and the high virulence in vivo after $96 \mathrm{~h}$ of infection, respectively. All analyses were performed using Graphpad Prism 6 and the degree of statistical significance considered was 95\% ( $p<0.05)$. The hierarchical clustering of the isolates according to the presence or absence of virulence genes was made with the program Excel Solver, with Matching coefficients and Group Average Linkage method.

\section{RESULTS}

\section{Genotypic and Phenotypic Characterization of EAEC Strains}

\section{Detection of Virulence Genes}

Through PCR assay, typical strains had eight to 13 virulence genes (mean $=9.7$ genes/strain), while atypical ones had zero to eight (mean $=2.6$ genes/strain $)(p<0.0001)$. Sen and sat genes were not observed in any strain, while the aap and $\operatorname{set} 1 \mathrm{~A}$ were present in all typical strains (Table 2).

Considering ExPEC genes, of the 20 EAEC clinical strains analyzed, only two (one typical strain - Q287A - and one atypical strain - Q185E) had at least two of the five genes searched and were classified as possible ExPEC (Table 2). Of the prototype strains, only the atypical strain C1096 was classified as a possible ExPEC, since it presented four of those virulence markers (Johnson et al., 2003).

\section{Siderophore and Hydrolytic Enzymes}

No strains showed phospholipase, protease, and esterase activity under the employed conditions. The only strain containing the hlyA gene (strain Q287A - typical EAEC) produced hemolysin (Table 2), but in such a reduced amount that it did not allow quantification (data not shown). Regarding the prototype strains, only the strain 042 produced protease, being classified as a weak producer $\left(D_{\text {colony }} / D_{\text {halo }}=0.76\right)$. In contrast, the mutant strain 042 did not show any enzymatic activity.

All analyzed strains produced siderophores. Sixteen strains were classified as "weak producers" and four were classified as "good producers" $\left(D_{\text {colony }} / D_{\text {halo }}<0.7\right)$, two of them being typical EAEC and two being atypical. There was no significant difference 
TABLE 2 | Genotypic and phenotypic characterization of EAEC strains (gray square for positivity) and \% survival of G. mellonella model $96 \mathrm{~h}$ after infection.

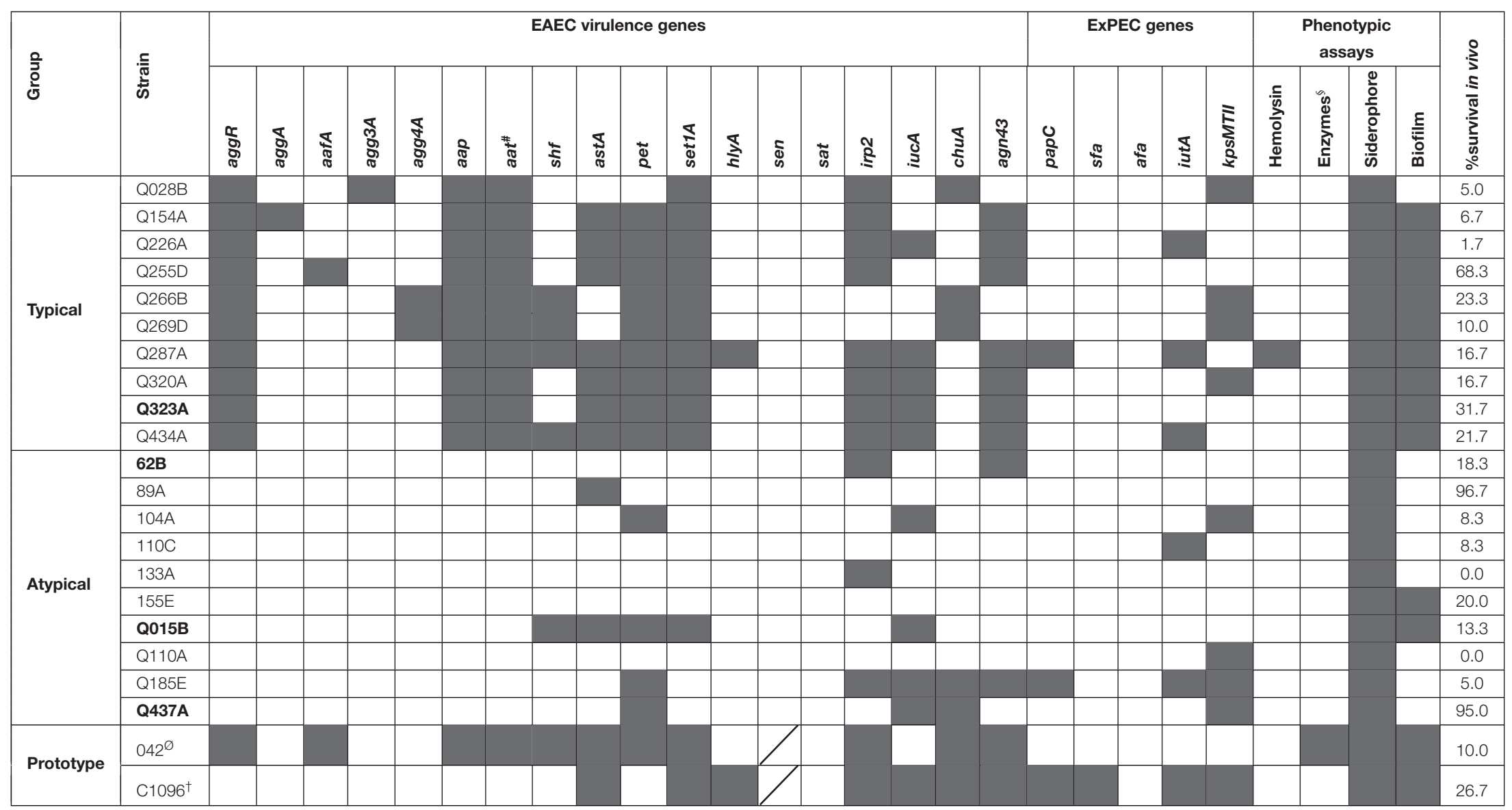

The strains highlighted in bold were isolated from children with diarrhea. Crossed cells in the table indicate not determined. \#Lozer et al. (2013); ${ }^{\circledR}$ Enzymes - phospholipase, esterase, and protease. ${ }^{\varnothing}$ Czeczulin et al. (1999); Okeke et al. (2004); Boisen et al. (2008), and this study. ${ }^{\dagger}$ Czeczulin et al. (1999) and this study. 
in the production of siderophore between typical and atypical EAEC strains $(p>0.05)$ (Figure 1). All prototype strains were classified as "weak producers."

\section{Biofilm Production}

Eight strains of typical EAEC were able to produce biofilm, whereas only two strains of atypical EAEC could do the same $(p<0.05)$ (Figure 2).

Both typical and atypical prototype strains were classified as biofilm producers, although strain 042 produced biofilm with a density 6.7 times greater than the C1096. In contrast, the mutant strain 042 lost the ability to form a biofilm.

\section{In vivo Assays in G. mellonella Model and Relation With Genotypic and Phenotypic Aspects}

\section{G. mellonella Killing Assay}

The strains of typical and atypical EAEC caused mortality of larvae in a classical inoculum-dependent manner, since the larvae
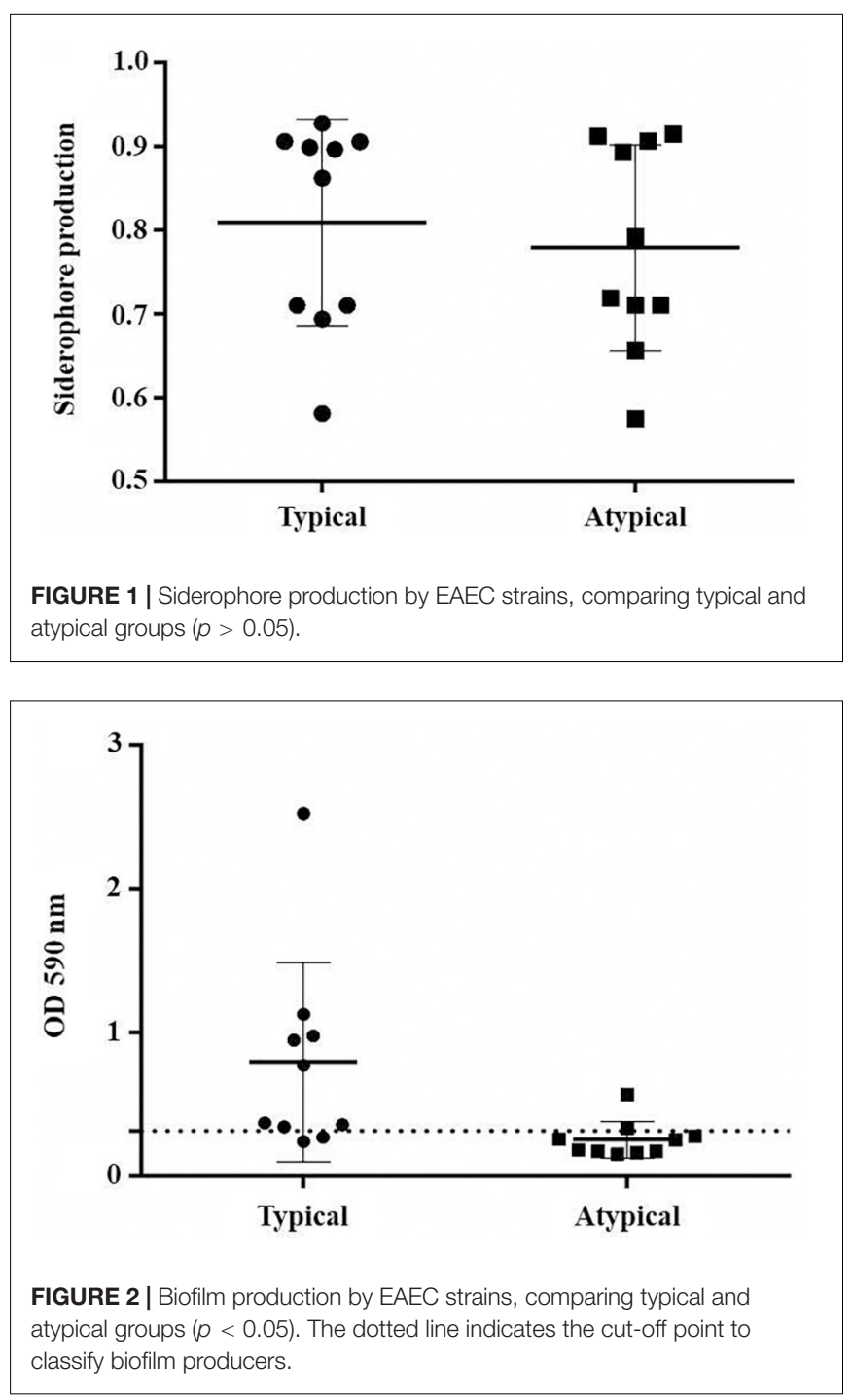

showed low mortality with lower inoculum of $10^{4} \mathrm{CFU} /$ larva (between 0 and 60\%) and 100\% mortality with higher inoculum of $10^{6}$ and $10^{7} \mathrm{CFU} /$ larva (data not shown). Therefore, the concentration $10^{5} \mathrm{CFU} /$ larva was the one that showed the highest differentiation among the strains, being this chosen for the virulence analyses. In addition, it was observed that the G. mellonella model is capable of differentiating levels of pathogenicity among EAEC strains (Figures 3A,B). Comparing the total of 600 analyzed larvae in each typical and atypical group, a significant difference occurred between the survival curves $(p=0.044)$ (Figure 3C).

The prototype strains of typical (EAEC 042) and atypical (C1096) EAEC showed high mortality in the model, with no significant difference between them $(p>0.05)$; while the nonpathogenic E. coli strain HB101 was not able to kill the larvae at any of the concentrations tested (Figure 3D). A significant reduction in the mortality was observed for the larvae inoculated with the EAEC $\operatorname{aggR}$ mutant strain 042 compared with the wild-type strain 042 at the concentration of $10^{5} \mathrm{CFU} /$ larva $(p=0.0001)$. While the larvae inoculated with the wild strain showed only $40 \%$ of survival in the first $24 \mathrm{~h}$, those inoculated with the mutant strain showed $80 \%$. The aggR mutant strain also showed lower virulence than the atypical prototype strain C1096 $(p=0.016)$ (Figure 3D).

Among the clinical strains, atypical EAEC showed the highest and lowest virulence in the model, with $0 \%$ survival after $96 \mathrm{~h}$ of infection (Q110A and 133A strains, with only one virulence gene) or survival close to $100 \%$ at the end of the experiment (89A and Q437A, with one and four genes, respectively). Among the typical EAEC, only one strain (Q255D, with nine virulence genes) demonstrated a lower virulence, with survival greater than $60 \%$ at the end of $96 \mathrm{~h}$ (Table 2 and Figures 4A,B). There was no significant difference in the percentage of survival between typical and atypical strains after $96 \mathrm{~h}$ of infection $(p>0.05)$ (Figure 4C). Moreover, when analyzing the strains individually, it was observed that most of the atypical strains (8/10) showed high virulence in the model, similar to typical strains $(9 / 10)$.

No statistical correlation was observed between the number of virulence genes and the percentage of survival after $96 \mathrm{~h}$ of infection $(r=0.12$ and $p>0.05)$. In addition, no virulence gene or phenotypic aspect was individually related to high virulence in vivo ( $p>0.05$ for all genes and phenotypic aspects analyzed). Besides this, the hierarchical clustering based on the repertory of virulence genes showed a clear separation between typical and atypical strains, with strains grouped in the same subcluster presenting different virulence for the larvae (Figure 5).

\section{Monitoring of Bacterial Growth in vivo}

The monitoring of bacterial growth, from zero up to $24 \mathrm{~h}$ after infection, showed that EAEC strains 042 (wild and $\operatorname{aggR}$ mutant) and C1096 growth within the larva, increasing its concentration in the first $6 \mathrm{~h}$ of infection followed by a stabilization of the bacterial load in $24 \mathrm{~h}$. On the other hand, the non-pathogenic strain (HB101) was eliminated from the hemolymph within $2 \mathrm{~h}$ after infection. In addition, the aggR mutant strain showed a lower concentration in the hemolymph after $4 \mathrm{~h}$ of infection, when compared to the wild-type strain (Figure 6A). 
A

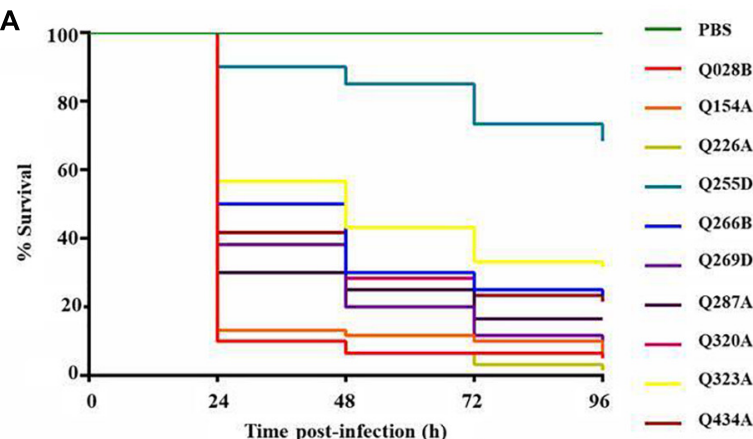

C

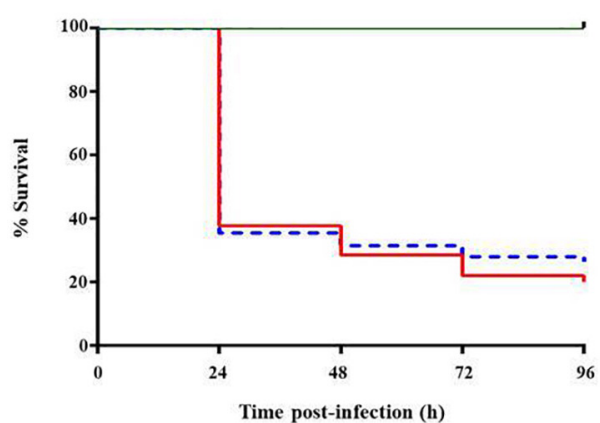

B

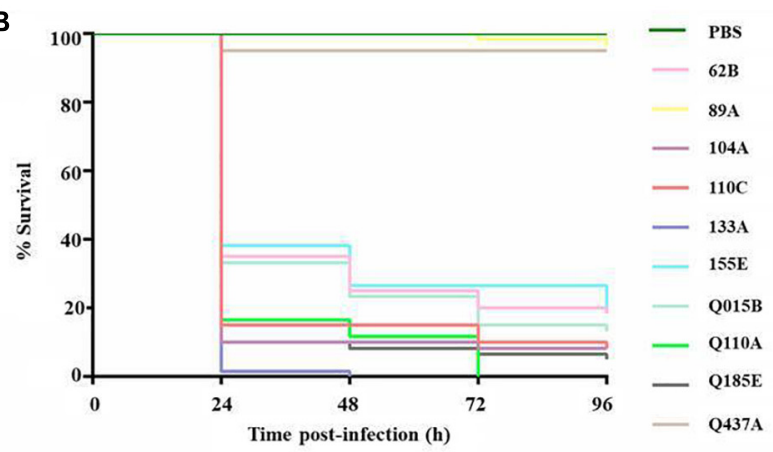

D

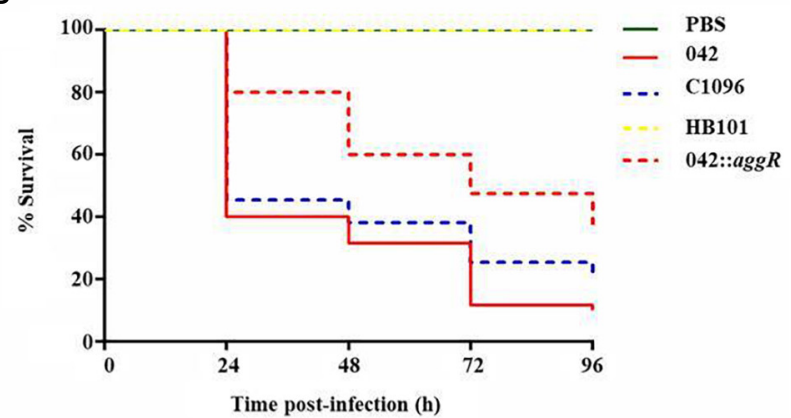

FIGURE 3 | Survival curve graphs of the G. mellonella inoculated with clinical and prototype strains. (A) 10 typical EAEC strains analyzed at the concentration of $10^{5} \mathrm{CFU} /$ larva. (B) 10 atypical EAEC strains analyzed at the concentration of $10^{5} \mathrm{CFU} /$ larva. (C) Survival curve by groups of strains (typical and atypical) $(p=0.04)$. (D) Prototype strains EAEC 042 (typical), C1096 (atypical), non-pathogenic E. coli strain HB101, and EAEC 042 aggR mutant at the concentration of 10 CFU/larva.

\section{Hemocyte Quantification During Infection}

In the first $2 \mathrm{~h}$ after infection, there was an increase in the quantity of circulating hemocytes after all inoculations. After $4 \mathrm{~h}$ of infection, the concentration decreased for strain C1096 and, for strain 042, after $6 \mathrm{~h}$; the aggR mutant behaved similarly to C1096 in all times analyzed (Figure 6B).

It was observed that only the larvae inoculated with both typical and atypical EAEC strains showed signs of melanization during infection, whereas the non-pathogenic E. coli strain HB101 did not induce this process (Figure 6C).

\section{DISCUSSION}

Typical EAEC are usually considered more virulent than atypical EAEC strains (Sarantuya et al., 2004; Morin et al., 2013). However, the outbreaks caused by the atypical ones (Čobeljić et al., 1996; Itoh et al., 1997), bring uncertainties regarding the difference in virulence among them. Therefore, to shed light on this issue the well-established G. mellonella in vivo model was used to compare virulence between typical and atypical EAEC clinical and prototype strains. We could show that atypical strains may be as virulent as typical strains, at least in the studied in vivo model, regardless of the analyzed genotypic or phenotypic aspects, but partially dependent of $\operatorname{aggR}$ for the prototype strain EAEC 042.
Initially, when establishing the optimal concentration of bacteria for the infection of $G$. mellonella larvae to the experiments, it was observed that larval death depends on the concentration of EAEC, as demonstrated in the first studies which analyzed clinical strains of typical EAEC in this model (Jønsson et al., 2016; Khalil et al., 2016). Although the killing capacity of the strain remains, our results do not perfectly match with those published previously by Jønsson et al. (2016). This was expected and is a current limitation of the G. mellonella model. The lack of universal genotypes of the larvae and the conditions adopted by each research group for feeding, reproduction, and maintenance of the animals can lead to quantitative differences in the results (Mowlds and Kavanagh, 2008; Olsen et al., 2011; Loh et al., 2013).

Although Sarantuya et al. (2004) proposed the $\operatorname{aggR}$ gene as a marker of truly virulent strains of EAEC, our experiments showed a similarity in virulence between typical and atypical strains in the G. mellonella model. However, the reduced mortality of the larvae infected with the $\operatorname{aggR}$ mutant EAEC strain 042 and the high virulence of atypical strains suggest that the virulence of EAEC seems to be related to the AggR regulon, but not exclusively. Corroborating with our results, a reduction in mortality was also observed for the $\operatorname{aggR}$ mutant EAEC strain 042 in the Caenorhabditis elegans model (França et al., 2013).

It is noteworthy that in the 042 strain, several other virulence factors are not under transcriptional control of AggR such as Pic (Protein involved in intestinal colonization), Pet (Plasmid encoded toxin), EAST (EAEC heat-stable enterotoxin 1), and 


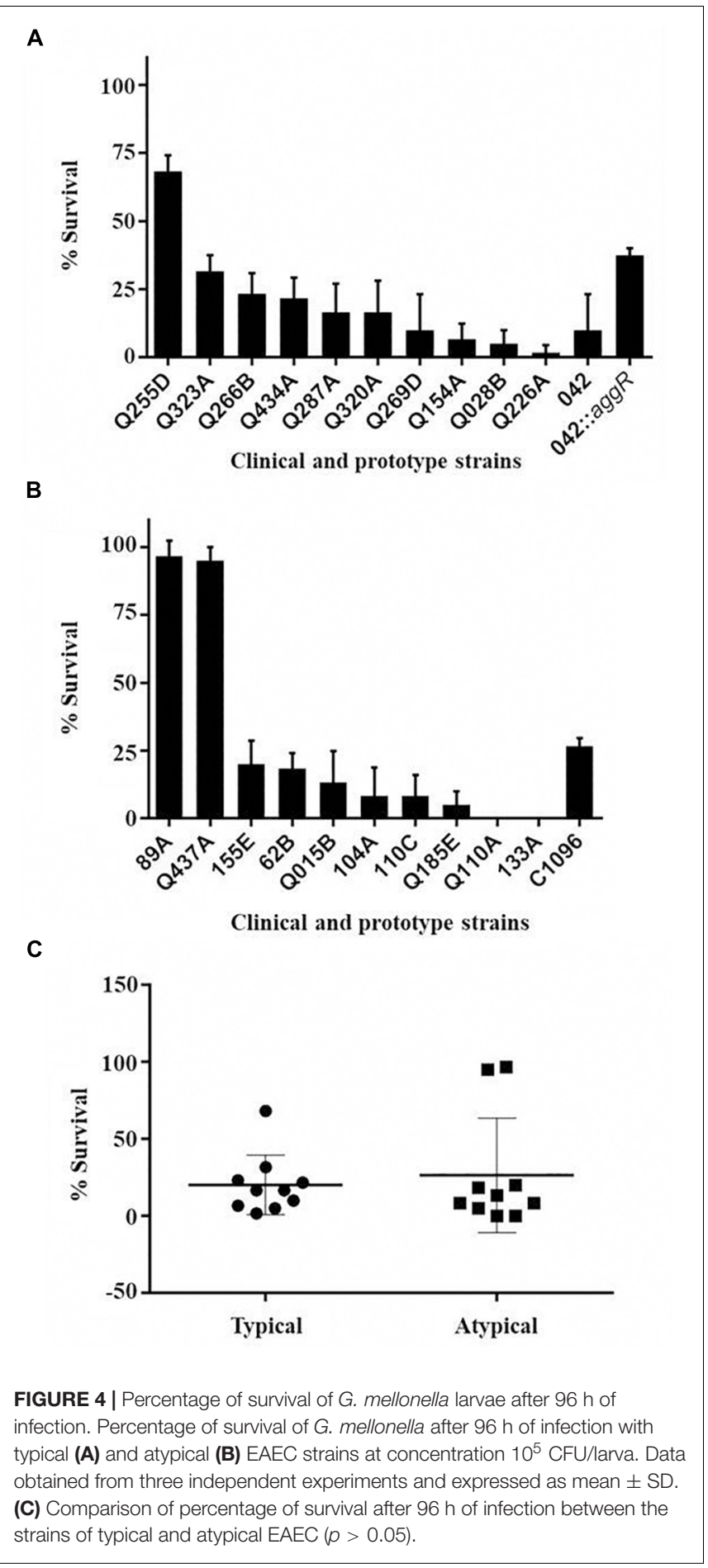

irp2 (Yersiniabactin biosynthetic gene) (Morin et al., 2013). Pic, a serine protease secreted by EAEC, is able to cleave molecules of the complement system, among other phenotypes, indicating its role in systemic infections (Abreu et al., 2015), which is the case of our model. Since 042:aggR continues expressing Pic, the virulence presented by this mutant in $G$. mellonella could be due to Pic action on the complement system. In fact, pic deletion in one E. coli strain isolated from a case of sepsis led to attenuation of the strain in a murine model of sepsis (unpublished data).

Although most strains of atypical EAEC showed high virulence, the almost $100 \%$ survival after infection with two strains (89A, Q437A) suggests that their virulence genes (astA, pet, iucA, and $\operatorname{chuA)}$ were not responsible for this characteristic in this model, or, if any of them contributed to it, it might not have been expressed. Actually, the virulence in the G. mellonella model could not be attributed to any of the genes described in the EAEC strains other than $\operatorname{aggR}$ gene, as also observed by França et al. (2013) with C. elegans model.

The non-pathogenic E. coli strain HB101 was not able to kill the larvae at any of the concentrations tested, as has been demonstrated for other non-pathogenic strains of $E$. coli in G. mellonella (Leuko and Raivio, 2012; Pereira et al., 2015; Jønsson et al., 2016). Indeed, the HB101 strain was totally eliminated from the hemolymph by the immune system after $2 \mathrm{~h}$ of infection in opposition to the prototype strains of typical or atypical EAEC that lead to death of the larvae. In this case, these strains multiply in the larva, and mortality is possibly caused by the increase in the amount of bacteria inside it, as also previously demonstrated in studies with Streptococcus pneumoniae, Actinobacillus pleuropneumoniae, and EAEC 042 (Evans and Rozen, 2012; Pereira et al., 2015; Jønsson et al., 2016). Interestingly, the survival rate of larvae inoculated with commensal E. coli strains ( $10^{5} \mathrm{CFU} /$ larva) was less than that of the HB101 strain but higher than that of the typical and atypical EAEC strains (data not shown). The adaptation and survival of commensal strains in human hosts probably gives greater virulence to larvae than the HB101 strain.

Infection by EAEC is accompanied by humoral immune response that leads to melanization of the G. mellonella larvae. After phagocytosis of the pathogen by hemocytes, melanin is deposited around microbes and is thought to facilitate bacterial killing (Browne et al., 2013). This response is observed after infecting $G$. mellonella with both typical and atypical EAEC, in which melanization began within $2 \mathrm{~h}$ after infection in the dorsal region of the larva, which contains the heart, and intensifies with the course of time. The larval dorsal vessel is an organ known to show a more intense immune response, due to the large amount of sessile hemocytes that are present on its surface and also of circulating hemocytes that are recruited together with the pathogen to the periphery of the dorsal vessel during infection (Pereira et al., 2015; Hillyer, 2018).

The cellular immune responses of $G$. mellonella were also investigated through hemocyte count and did not demonstrate discrepancy between typical and atypical EAEC prototype strains. There was an increase in the amount of circulating hemocytes, followed by a reduction. It may occur, on one hand, due to the cytotoxic activity of the bacteria on the cells, as demonstrated after infection of G. mellonella by Pseudomonas aeruginosa (Mizerska-dudka and Andrejko, 2014), and, on the other hand, due to their recruitment to the heart surface by the sessile hemocytes to aid the elimination of the pathogen (Pereira et al., 2015).

We also observed whether the G. mellonella model would be able to sort out strains at different levels of pathogenicity. 


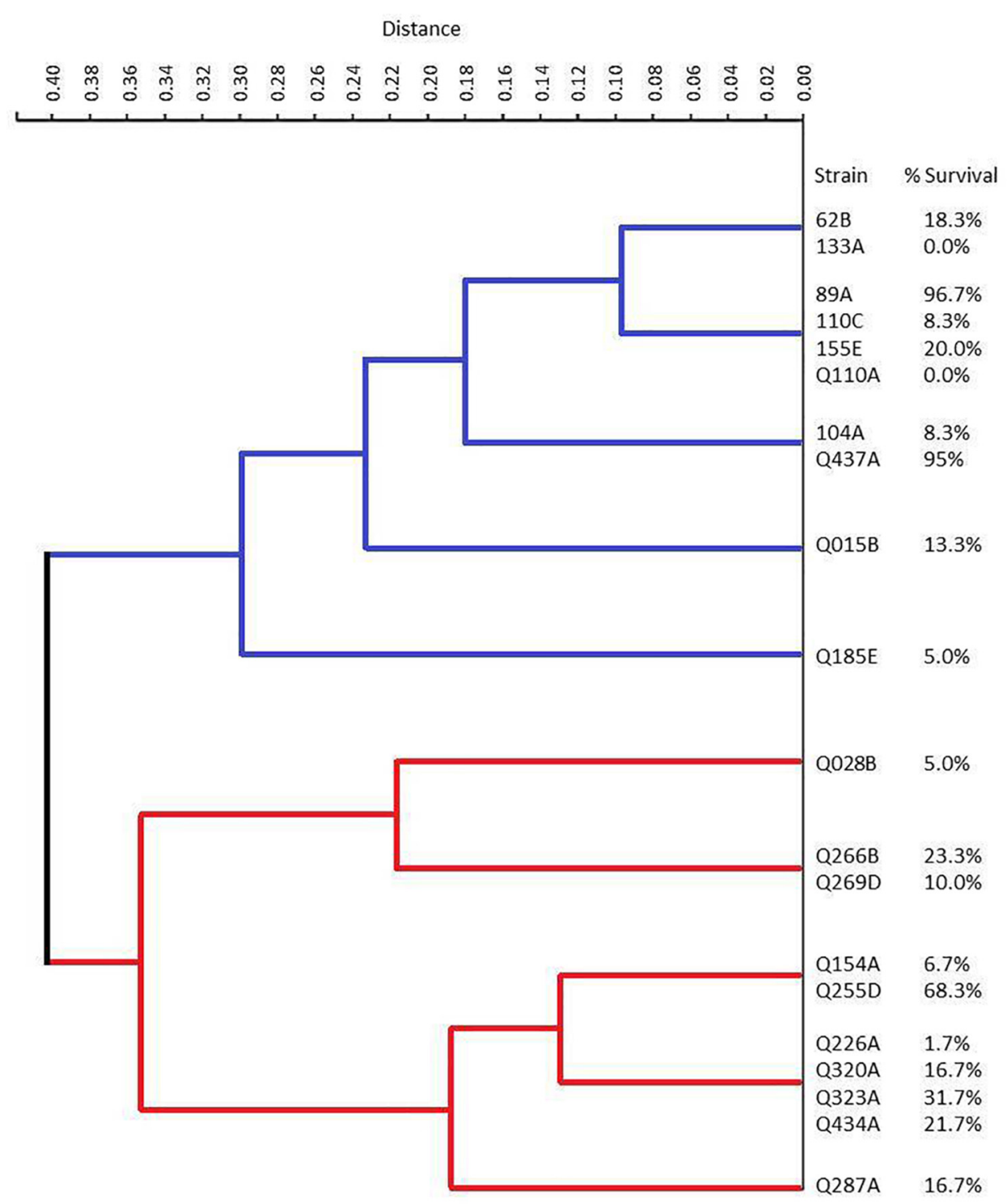

FIGURE 5 | Dendrogram representation of the hierarchical clustering of the isolates according to the presence or absence of virulence gene with the corresponding EAEC strains and survival percentage. Red and blue lines represent the typical and atypical strains, respectively.

However, although a large repertoire of virulence genes beyond phenotypic features was analyzed, no relation was observed. While the strain (Q255D) with nine of the studied genes had more than 60\% survival, strains (Q110A and 133A) with one of the investigated genes including ExPEC genes, led to $100 \%$ mortality. Thus, factors currently unknown may be involved in the in vivo virulence of both typical and atypical EAEC.

Jønsson et al. (2016) suggested that AAF adhesin was related to the high virulence of EAEC in the G. mellonella model, by comparison with the Afa/Dr adhesin (Dr binding adhesins) which correlated with the pathogenicity of ExPEC (Ciesielczuk et al., 2015), although they did not perform any virulence assay of strains with and without AAF. Considering that, among the five the strains tested in our study that had some of the AAFs, four of them had a high virulence to the larvae (below 40\% survival), and that most strains with high virulence $(13 / 17) \mathrm{did}$ not present the AAF genes, we suggest that additional factors could also be related to virulence beyond these genes, if in fact they participate in it. Therefore, the lack of relation between the virulence EAEC genes and virulence in the model leads us to suggest that unknown virulence factors may contribute to larval mortality.

In contrast, a study that analyzed the virulence of ExPEC in G. mellonella found a correlation between the number of virulence genes and the mortality of the larvae (Williamson et al., 2014). Our two EAEC strains with genes of ExPEC showed high virulence, as well as those without these genes. 


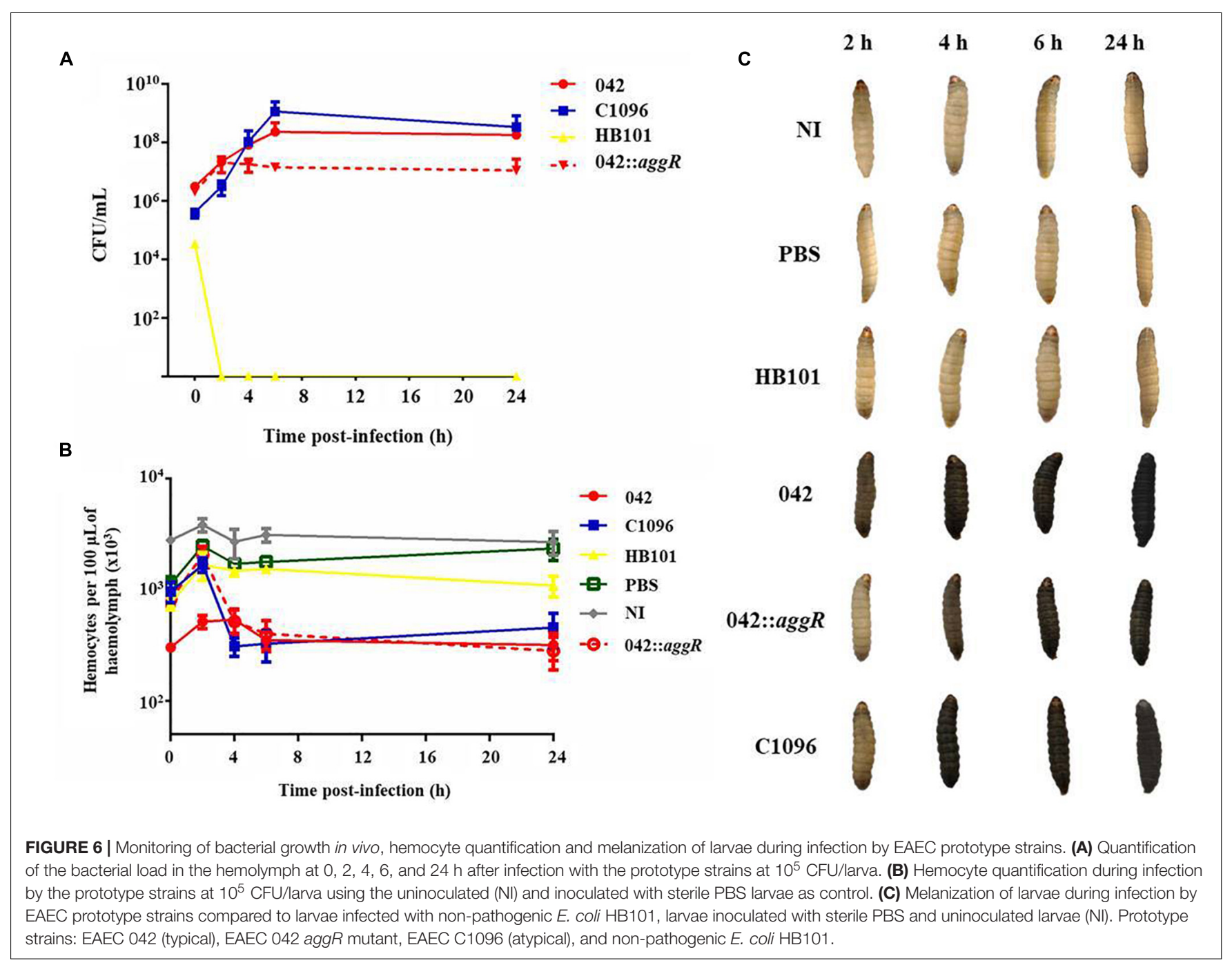

In relation to the phenotypic characteristics of virulence, there was also no significant difference between the typical and atypical EAEC groups regarding the production of siderophores. Despite the importance of the enzymes in the pathogenesis of several microorganisms (Guignot et al., 2000; Ruiz-Perez and Nataro, 2014; Ramos et al., 2016), no significant production of these virulence factors by the analyzed strains was observed. Biofilm production, significantly associated with typical EAEC, was not related to in vivo virulence, since atypical strains that showed high virulence had no biofilm production. Interestingly, it was observed that the aggR mutant strain EAEC 042 did not show biofilm and protease production, such as the wild type strain 042, demonstrating the importance of this regulon for the expression of some virulence features. It has already been proven that the AggR regulon regulates several virulence genes, including genes involved in biofilm production (Morin et al., 2013).

The results obtained in this study demonstrate important aspects of the virulence of typical and atypical EAEC in vivo. It was observed that, contrary to what is suggested in the literature, atypical EAEC strains may be as virulent as typical ones, and their virulence is not due only to the AggR regulon and the genes regulated by it. Besides this, no relation was observed between phenotypic and genotypic characteristics of virulence and in vivo virulence in the G. mellonella model.

\section{DATA AVAILABILITY}

The datasets for this manuscript are not publicly available because datasets are available on request. The raw data supporting the conclusions of this manuscript will be made available by the authors, without undue reservation, to any qualified researcher. Requests to access the datasets should be directed to LS, liliana.spano@ufes.br.

\section{AUTHOR CONTRIBUTIONS}

LS, RS, AS, and WE designed the study. CG, MP, and AG performed the experiments and analyzed the data. CG, LS, 
and WE wrote the manuscript. All co-authors reviewed and commented on the manuscript.

\section{FUNDING}

This work was supported by the Fundação de Amparo à Pesquisa do Espírito Santo (FAPES), Fundação de Amparo à Pesquisa do Estado do Rio de Janeiro (FAPERJ), the Conselho Nacional de

\section{REFERENCES}

Abreu, A. G., Fraga, T. R., Granados Martínez, A. P., Kondo, M. Y., Juliano, M. A., Juliano, L., et al. (2015). The serine protease pic from enteroaggregative Escherichia coli mediates immune evasion by the direct cleavage of complement proteins. J. Infect. Dis. 212, 106-115. doi: 10.1093/infdis/jiv013

Bernier, C., Gounon, P., and Le Bouguénec, C. (2002). Identification of an aggregative adhesion fimbria (aaf) type iii-encoding operon in enteroaggregative Escherichia coli as a sensitive probe for detecting the aaf-encoding operon family. Infect. Immun. 70, 4302-4311. doi: 10.1128/IAI.70.8.4302

Boisen, N., Struve, C., Scheutz, F., Krogfelt, K. A., and Nataro, J. P. (2008). New adhesin of enteroaggregative Escherichia coli related to the afa/dr/aaf family. Infect. Immun. 76, 3281-3292. doi: 10.1128/IAI.01646-07

Brown, S. E., Howard, A., Kasprzak, A. B., Gordon, K. H., and East, P. D. (2009). A peptidomics study reveals the impressive antimicrobial peptide arsenal of the wax moth Galleria mellonella. Insect Biochem. Mol. Biol. 39, 792-800. doi: 10.1016/j.ibmb.2009.09.004

Browne, N., Heelan, M., and Kavanagh, K. (2013). An analysis of the structural and functional similarities of insect hemocytes and mammalian phagocytes. Virulence. 4, 597-603. doi: 10.4161/viru.25906

Ciesielczuk, H., Betts, J., Phee, L., Doumith, M., Hope, R., Woodford, N., et al. (2015). Comparative virulence of urinary and bloodstream isolates of extraintestinal pathogenic Escherichia coli in a Galleria mellonella model. Virulence 6, 145-151. doi: 10.4161/21505594.2014.988095

Ćobeljić, M., Miljković-Selimović, B., Paunović-Todosijević, D., Veliv̌ković, Z., Lepšanović, Z., Zec, N., et al. (1996). Enteroaggregative Escherichia coli associated with an outbreak of diarrhea in a neonatal nursery ward. Epidemiol. Infect. 117, 11-16. doi: 10.1017/s0950268800001072

Cook, S. M., and Mcarthur, J. D. (2013). Developing Galleria mellonella as a model host for human pathogens. Virulence. 4, 350-353. doi: 10.4161/viru. 25240

Czeczulin, J. R., Whittam, T. S., Henderson, I. R., Navarro-garcia, F., and Nataro, J. P. (1999). Phylogenetic analysis of enteroaggregative and diffusely adherent Escherichia coli. Infect. Immun. 67, 2692-2699.

Elias, W. P., Czeczulin, J. R., Henderson, I. R., Trabulsi, L. R., and Nataro, J. P. (1999). Organization of biogenesis genes for aggregative adherence fimbria II defines a virulence gene cluster in enteroaggregative Escherichia coli. J. Bacteriol. $181,1779-1785$.

Evans, B. A., and Rozen, D. E. (2012). A Streptococcus pneumoniae infection model in larvae of the wax moth Galleria mellonella. Eur. J. Clin. Microbiol. Infect. Dis. 31, 2653-2660. doi: 10.1007/s10096-012-1609-7

França, F. L. S., Wells, T. J., Browning, D. F., Nogueira, R. T., Sarges, F. S., Pereira, A. C., et al. (2013). Genotypic and phenotypic characterisation of enteroaggregative Escherichia coli from Children in Rio de Janeiro, Brazil. Plos One 8:e69971. doi: 10.1371/journal.pone.0069971

Guignot, J., Breard, J., Bernet-camard, M. F., Peiffer, I., Nowicki, B. J., Servin, A. L., et al. (2000). Pyelonephritogenic diffusely adhering Escherichia coli EC7372 harboring Dr-II adhesin carries classical uropathogenic virulence genes and promotes cell lysis and apoptosis in polarized epithelial caco2/TC7 cells. Infect. Immun. 68, 7018-7027. doi: 10.1128/iai.68.12.7018-7027. 2000

Hillyer, J. F. (2018). Insect heart rhythmicity is modulated by evolutionarily conserved neuropeptides and neurotransmitters. Curr. Opin. Insect Sci. 29, 41-48. doi: 10.1016/j.cois.2018.06.002
Desenvolvimento Científico e Tecnológico (CNPq), and in part by the Coordenação de Aperfeiçoamento de Pessoal de Nível Superior - Brasil (CAPES) - Finance Code 001.

\section{ACKNOWLEDGMENTS}

We would like to thank Dr. Isabel Cristina Affonso Scaletsky for kindly providing the EAEC 042 strain.

Huang, D. B., Jiang, Z. D., and Dupont, H. L. (2003). Association of virulence factor-positive and negative enteroaggregative Escherichia coli and occurrence of clinical illness in travelers from the united states to Mexico. Am. J. Trop. Med. Hygiene 69, 506-508. doi: 10.4269/ajtmh.2003.69.506

Huang, D. B., Mohamed, J. A., Nataro, J. P., DuPont, H. L., Jiang, Z. D., and Okhuysen, P. C. (2007). Virulence characteristics and the molecular epidemiology of enteroaggregative Escherichia coli isolates from travellers to developing countries. J. Med. Microbiol. 56, 1386-1392. doi: 10.1099/jmm.0. 47161-0

Itoh, Y., Nagano, I., Kunishima, M., and Ezaki, T. (1997). Laboratory investigation of enteroaggregative Escherichia coli O untypeable:h10 associated with a massive outbreak of gastrointestinal illness. J. Clin. Microbiol. 35, 2546-2550.

Jensen, B. H., Olsen, K. E. P., Struve, C., Krogfelt, K. A., and Petersen, A. M. (2014). Epidemiology and clinical manifestations of enteroaggregative Escherichia coli. Clin. Microbiol. Rev. 27, 614-630. doi: 10.1128/CMR.00112-3

Johnson, J. R., Murray, A. C., Gajewski, A., Sullivan, M., Snippes, P., Kuskowski, M. A., et al. (2003). Isolation and molecular characterization of nalidixic acid-resistant extraintestinal pathogenic Escherichia coli from retail chicken products. Antimicrob. Agents Chemother. 47, 2161-2168. doi: 10.1128/AAC.47. 7.2161

Johnson, J. R., and Stell, A. L. (2000). Extended virulence genotypes of Escherichia coli strains from patients with urosepsis in relation to phylogeny and host compromise. J. Infect. Dis. 181, 261-272. doi: 10.1086/315217

Jønsson, R., Struve, C., Jenssen, H., and Krogfelt, K. A. (2016). The wax moth Galleria mellonella as a novel model system to study enteroaggregative Escherichia coli pathogenesis. Virulence 8, 1894-1899. doi: 10.1080/21505594. 2016.1256537

Khalil, U., Younus, M., Asghar, N., Siddiqui, F., Gomez-Duarte, O. G., Wren, B. W., et al. (2016). Phenotypic and genotypic characterization of enteroaggregative Escherichia coli isolates from pediatric population in Pakistan. APMIS 7, 872-880. doi: 10.1111/apm.12577

Le Bouguenec, C., Archambaud, M., and Labigne, A. (1992). Rapid and specific detection of the pap, afa, and sfa adhesin- encoding operons in uropathogenic Escherichia coli strains by polymerase chain reaction. J. Clin. Microbiol. 30, 1189-1193.

Le Bouguenec, C., Lalioui, L., Merle, L. D., Jouve, M., Courcoux, P., Bouzari, S., et al. (2001). Characterization of afae adhesins produced by extraintestinal and intestinal human Escherichia coli isolates: PCR assays for detection of afa adhesins that do or do not recognize Dr blood group antigens. J. Clin. Microbiol. 39, 1738-1745. doi: 10.1128/JCM.39.5.1738

Lee, Y. S., Yun, E. K., Jang, W. S., Kim, I., Lee, J. H., Park, S. Y., et al. (2004). Purification, cDNA cloning and expression of an insect defensin from the great wax moth, Galleria mellonella. Insect Mol. Biol. 13, 65-72. doi: 10.1111/j.13652583.2004.00462.x

Leuko, S., and Raivio, L. T. (2012). Mutations that impact the enteropathogenic Escherichia coli cpx envelope stress response attenuate virulence in Galleria mellonella. Infect. Immun. 80, 3077-3085. doi: 10.1128/IAI.00081-12

Loh, J. M., Adenwalla, N., Wiles, S., and Proft, T. (2013). Galleria mellonella larvae as an infection model for group a Streptococcus. Virulence. 4, 419-428. doi: 10.4161/viru. 24930

Lozer, D. M., Souza, T. B., Monfardini, M. V., Vicentini, F., Kitagawa, S. S., Scaletsky, I. C. A., et al. (2013). Genotypic and phenotypic analysis of diarrheagenic Escherichia coli strains isolated from Brazilian children living in low socioeconomic level communities. BMC Infect. Dis. 13:418. doi: 10.1186/ 1471-2334-13-418 
Mead, G. P., Ratcliffe, N. A., and Renwrantz, L. R. (1986). The separation of insect haemocyte types on Percoll gradients; methodology and problems. J. Insect Physiol. 32, 167-177. doi: 10.1016/0022-1910(86)90137-x

Mendez-Arancibia, E., Vargas, M., Soto, S., Ruiz, J., Kahigwa, E., Schellenberg, D., et al. (2008). Prevalence of different virulence factors and biofilm production in enteroaggregative Escherichia coli isolates causing diarrhea in children in ifakara (Tanzania). Am. J. Trop. Med. Hygiene. 78, 985-989. doi: 10.4269/ajtmh.2008. 78.985

Mizerska-dudka, M., and Andrejko, M. (2014). Galleria mellonella hemocytes destruction after infection with Pseudomonas aeruginosa. J. Basic Microbiol. 54, 232-246. doi: 10.1002/jobm.201200273

Moreno, A. C. R., Filho, A. F., Gomes, T. A. T., Ramos, S. T. S., Montemor, L. P. G., Tavares, V. C., et al. (2010). Etiology of childhood diarrhea in the northeast of Brazil: significant emergent diarrheal pathogens. Diagn. Microbiol. Infect. Dis. 66, 50-57. doi: 10.1016/j.diagmicrobio.2008.03.017

Morin, N., Santiago, A. E., Ernst, R. K., Guillot, S. J., and Nataro, J. P. (2013). Characterization of the AggR regulon in enteroaggregative Escherichia coli. Infect. Immun. 81, 122-132. doi: 10.1128/IAI.00676-612

Morin, N., Tirling, C., Ivison, S. M., Kaur, P. A., Nataro, J. P., and Steiner, T. S. (2010). Autoactivation of the AggR regulator of enteroaggregative Escherichia coli in vitro and in vivo. FEMS Immunol. Med. Microbiol. 58, 344-355. doi: 10.1111/j.1574-695X.2009.00645.x

Mowlds, P., and Kavanagh, K. (2008). Effect of pre-incubation temperature on susceptibility of Galleria mellonella larvae to infection by Candida albicans. Mycopathologia 165, 5-12. doi: 10.1007/s11046-007-9069-9

Nataro, J. P., Deng, Y., Cookson, S., Cravioto, A., Savarino, S. J., Guers, L. D., et al. (1995). Heterogeneity of enteroaggregative Escherichia coli virulence demonstrated in volunteers. J. Infect. Dis. 171, 465-468. doi: 10.1093/infdis/171. 2.465

Navarro-Garcia, F., Gutierrez-Jimenez, J., Garcia-Tovar, C., Castro, L. A., SalazarGonzalez, H., and Cordova, V. (2010). Pic, an autotransporter protein secreted by different pathogens in the Enterobacteriaceae family, is a potent mucus secretagogue. Infect. Immun. 78, 4101-4109. doi: 10.1128/IAI. $00523-510$

Okeke, I. N., Lamikanra, A., Czeczulin, J., Dubovsky, F., Kaper, J. B., and Nataro, J. P. (2000). Heterogeneous virulence of enteroaggregative Escherichia coli strains isolated from children in southwest Nigeria. J. Infect. Dis. 181, $252-260$.

Okeke, I. N., Scaletsky, I. C. A., Soars, E. H., Macfarlane, L. R., and Torres, A. G. (2004). Molecular epidemiology of the iron utilization genes of enteroaggregative Escherichia coli. J. Clin. Microbiol. 42, 36-44. doi: 10.1128/ JCM.42.1.36

Okeke, I. N., Wallace-Gadsden, F., Simons, H. R., Matthews, N., Labar, A. S., Hwang, J., et al. (2010). Multi-locus sequence typing of enteroaggregative Escherichia coli isolates from Nigerian children uncovers multiple lineages. Plos One 5:e14093. doi: 10.1371/journal.pone.0014093

Okhuysen, P. C., and Dupont, H. L. (2010). Enteroaggregative Escherichia coli (EAEC): a cause of acute and persistent diarrhea of worldwide importance. J. Infect. Dis. 202, 503-505. doi: 10.1086/654895

Olsen, R. J., Watkins, M. E., Cantu, C. C., Beres, S. B., and Musser, J. M. (2011). Virulence of serotype M3 group A Streptococcus strains in wax worms (Galleria mellonella larvae). Virulence 2, 111-119. doi: 10.4161/viru.2.2.14338

Opintan, J. A., Newman, M. J., Ayeh-kumi, P. F., Affrim, R., Gepi-attee, R., Sevilleja, J. E. A. D., et al. (2010). Pediatric diarrhea in southern ghana: etiology and association with intestinal inflammation and malnutrition. Am. J. Trop. Med. and Hygiene 83, 936-943. doi: 10.4269/ajtmh.2010.09-0792

Park, S. Y., Kim, C. H., Jeong, W. H., Lee, J. H., Seo, S. J., Han, Y. S., et al. (2005). Effects of Two hemolymph proteins on humoral defense reactions in the wax moth, Galleria mellonella. Dev. Comp. Immunol. 29, 43-51. doi: 10.1016/j.dci. 2004.06.001

Pereira, M. F., Ciro, C. R., Queiroz, M. V., Martins, G. F., Isaac, C., Bosse, J. T., et al. (2015). Galleria mellonella is an effective model to study Actinobacillus pleuropneumoniae infection. Microbiology. 161, 387-400. doi: 10.1099/mic.0. 083923-0

Price, M. F., Wilkinson, I. D., and Gentry, L. O. (1982). Plate method for detection of phospholipase activity in Candida albicans. Sabouraudia 20, 7-14. doi: 10.1080/00362178285380031
Ramarao, N., Nielsen-Leroux, C., and Lereclus, D. (2012). The insect Galleria mellonella as a powerful infection model to investigate bacterial pathogenesis. J. Vis. Exp. 70, 1-7. doi: 10.3791/4392

Ramos, L. S., Branquinha, M. H., and Santos, A. L. S. (2016). Different classes of hydrolytic enzymes produced by multidrug-resistant yeasts comprising the Candida haemulonii complex. Med. Mycol. 55, 228-232. doi: 10.1093/mmy/ myw065

Roche, J. K., Cabel, A., Sevilleja, J., Nataro, J., and Guerrant, R. L. (2010). Enteroaggregative Escherichia coli (EAEC) impairs growth while malnutrition worsens EAEC infection: a novel murine model of the infection malnutrition cycle. J. Infect. Dis. 22908, 506-514. doi: 10.1086/654894

Ruiz, J., Navia, M. M., Vila, J., and Gascón, J. (2002). Prevalence of the sat gene among clinical isolates of Shigella Spp. causing travelers' diarrhea: geographical and specific differences. J. Clin. Microbiol. 40, 1565-1566. doi: 10.1128/JCM.40. 4.1565

Ruiz-Perez, F., and Nataro, J. P. (2014). Bacterial serine proteases secreted by the autotransporter pathway: classification, specificity and role in virulence. Cell. Mol. Life Sci. 71, 745-770. doi: 10.1007/s00018-013-1355-8

Sarantuya, J., Nishi, J., Wakimoto, N., Erdene, S., Nataro, J. P., Sheikh, J., et al. (2004). Typical enteroaggregative Escherichia coli is the most prevalent pathotype among E. coli strains causing diarrhea in mongolian children. J. Clin. Microbiol. 42, 133-139. doi: 10.1128/JCM.42.1.133

Searle, L. J., Méric, G., Porcelli, I., Sheppard, S. K., and Lucchini, S. (2015). Variation in siderophore biosynthetic gene distribution and production across environmental and faecal populations of Escherichia coli. Plos One 10:e117906. doi: 10.1371/journal.pone.0117906

Shaik, H. A., and Sehnal, F. (2009). Hemolin expression in the silk glands of Galleria mellonella in response to bacterial challenge and prior to cell disintegration. J. Insect Physiol. 55, 781-787. doi: 10.1016/j.jinsphys.2009. 04.010

Sheikh, J., Hicks, S., Dall'Agnol, M., Phillips, A. D., and Nataro, J. P. (2001). Roles for Fis and YafK in biofilm formation by enteroaggregative Escherichia coli. Mol. Microbiol. 41, 983-997. doi: 10.1046/j.1365-2958.2001.02512.x

Soderhall, K., and Cerenius, L. (1998). Role of the prophenoloxidase-activating system in invertebrate immunity. Innate Immun. 10, 23-28. doi: 10.1016/ s0952-7915(98)80026-5

Spano, L. C., Cunha, K. F., Monfardini, M. V., Fonseca, R. C. B., and Scaletsky, I. C. A. (2017). High prevalence of diarrheagenic Escherichia coli carrying toxinencoding genes isolated from children and adults in southeastern Brazil. BMC Infect. Dis. 17:773. doi: 10.1186/s12879-017-2872-0

Stepanovic, S., Vukovic, D., Hola, V., Bonaventura, G., Slobodanka, D., Cirkovic, I., et al. (2007). Quantification of biofilm in microtiter plates: overview of testing conditions and practical recommendations for assessment of biofilm production by Staphylococci. APMIS 115, 891-899. doi: 10.1111/j.1600-0463. 2007.apm_630.x

Tsai, C. J., Loh, J. M. S., and Proft, T. (2016). Galleria mellonella infection models for the study of bacterial diseases and for antimicrobial drug testing. Virulence 7, 214-229. doi: 10.1080/21505594.2015.1135289

Vila, J., Vargas, M., Henderson, I. R., Gascon, J., and Nataro, J. P. (2000). Enteroaggregative Escherichia coli virulence factors in traveler's diarrhea strains. J. Infect. Dis. 182, 1780-1783. doi: 10.1086/317617

Williamson, D. A., Mills, G., Johnson, J. R., Porter, S., and Wiles, S. (2014). In vivo correlates of molecularly inferred virulence among extraintestinal pathogenic Escherichia coli (ExPEC) in the wax moth Galleria mellonella model system. Virulence 5, 388-393. doi: 10.4161/viru.27912

Conflict of Interest Statement: The authors declare that the research was conducted in the absence of any commercial or financial relationships that could be construed as a potential conflict of interest.

Copyright (C) 2019 Guerrieri, Pereira, Galdino, Santos, Elias, Schuenck and Spano. This is an open-access article distributed under the terms of the Creative Commons Attribution License (CC BY). The use, distribution or reproduction in other forums is permitted, provided the original author(s) and the copyright owner(s) are credited and that the original publication in this journal is cited, in accordance with accepted academic practice. No use, distribution or reproduction is permitted which does not comply with these terms. 